\title{
Organic Hydroperoxide-Induced Activation of Liver Microsomal Glutathione $S$-Transferase of Rats In Vitro
}

\author{
Yoko Aniya and Ai Daido \\ Laboratory of Physiology and Pharmacology, School of Health Sciences, Faculty of Medicine, University of the Ryukyus, \\ 207 Uehara, Nishihara, Okinawa 903-01, Japan \\ Received October 5, 1992 Accepted January 22, 1993
}

\begin{abstract}
The effect of $t$-butyl hydroperoxide ( $\mathrm{t}-\mathrm{BuOOH})$, cumene hydroperoxide $(\mathrm{CuOOH})$ or linoleic acid hydroperoxide (linoleic- $\mathrm{OOH}$ ) on liver microsomal glutathione $S$-transferase of rats was studied in vitro. When microsomes were incubated with either $100 \mu \mathrm{M}$ t-BuOOH or $25 \mu \mathrm{M} \mathrm{CuOOH}$, glutathione $S$ transferase activity was increased 1.5-fold; activity was further increased to 2.2-fold in the presence of small amounts of glutathione. The same amounts of dithiothreitol or cysteine did not enhance the t-BuOOH or $\mathrm{CuOOH}$-induced increase in transferase activity. The transferase activity was also increased 1.4-fold by 10 $\mu \mathrm{M}$ linoleic-OOH plus $1 \mu \mathrm{M}$ glutathione. The increase in microsomal glutathione $S$-transferase activity after treatment of microsomes with $\mathrm{t}-\mathrm{BuOOH}$ in the presence of glutathione was completely reversed by addition of dithiothreitol, whereas the activation of the transferase caused by $\mathrm{t}-\mathrm{BuOOH}$ in the absence of glutathione was not reversed. Although microsomal glutathione $S$-transferase also possesses glutathione peroxidase activity, only transferase activity was increased by $\mathrm{t}-\mathrm{BuOOH}$ in either the presence or absence of glutathione. These data indicate that microsomal glutathione $S$-transferase is activated by organic hydroperoxides in either the absence or presence of small amounts of glutathione, suggesting an activation of the transferase by thiol oxidation of the cysteine residue.
\end{abstract}

Keywords: Glutathione transferase (liver microsome), $t$-Butyl hydroperoxide, Cumene hydroperoxide, Linoleic acid hydroperoxide, Enzyme activation

Glutathione $S$-transferases (EC. 2.5.1.18) play important roles in the detoxication and excretion of xenobiotics (1-3). Rat liver contains at least eight cytosolic forms and one microsomal form of glutathione $S$-transferase, and both forms are distinguished by immunochemical and structural analyses $(4,5)$. Microsomal glutathione $S$-transferase is a trimer that contains one cysteine residue per subunit $(6,7)$. Cytosolic isozymes are, on the other hand, dimer proteins. Microsomal glutathione $S$ transferase is activated by various methods such as covalent modification of the sulfhydryl group by $N$-ethylmaleimide (8), thiol/disulfide exchange $(9,10)$, limited proteolysis (11) or heating (12). Previous reports demonstrated that microsomal glutathione $S$-transferase is also activated by reactive oxygens (13-15). Evidence shows that an activation of microsomal glutathione $S$ transferase by reactive oxygens such as hydrogen peroxide is due to oxidation of the sulfhydryl group of the enzyme, forming a disulfide bond. In addition to these in vitro studies, oxidative stress-induced activation of microsomal glutathione $S$-transferase was demonstrated by ischemia/reperfusion or perfusion with hydrogen peroxide of isolated rat liver (16). Since lipid hydroperoxides or 4-hydroxyalkenals, which are known as substrates for glutathione $S$-transferase $(17,18)$, are generated during oxidative stress, it was expected that microsomal glutathione $S$-transferase is activated by its own substrates, resulting in detoxication of toxic products. To evaluate this possibility, the effects of organic hydroperoxides including fatty acid hydroperoxides on microsomal glutathione $S$-transferase were investigated.

\section{MATERIALS AND METHODS}

\section{Animals and preparation of microsomes}

Male Sprague Dawley rats (200-300 g), after overnight starvation, were killed by decapitation and then used for the experiment. The liver was removed after perfusion in situ with ice-cold $1.15 \%$ potassium chloride solution. Liver microsomes were prepared as previously described 
(13).

In vitro treatment of microsomes and enzyme assay

Microsomes $(4-5 \mathrm{mg} / \mathrm{ml})$ were suspended in $0.05 \mathrm{M}$ potassium phosphate buffer ( $\mathrm{pH}$ 7.4) containing $0.3 \mathrm{mM}$ EDTA and $0.25 \mathrm{M}$ sucrose and incubated with $t$-butyl hydroperoxide (t-BuOOH), cumene hydroperoxide $(\mathrm{CuOOH})$ or linoleic acid hydroperoxide (linoleic-OOH) in the presence or absence of glutathione in $0.05 \mathrm{M}$ potassium phosphate buffer $(\mathrm{pH} \mathrm{7.4)}$ at room temperature $\left(24^{\circ} \mathrm{C}-28^{\circ} \mathrm{C}\right)$ for the indicated times. Glutathione $S$-transferase activity after incubation was measured by the method of Habig et al. (19) with $1 \mathrm{mM}$ 1-chloro-2,4dinitrobenzene and $5 \mathrm{mM}$ glutathione as substrates. Glutathione peroxidase activity towards $\mathrm{CuOOH}$ was assayed by the method of Reddy et al. (20). Protein concentration was determined by the method of Lowry et al. (21).

\section{Chemicals}

Reduced glutathione, glutathione reductase, cumene hydroperoxide and $t$-butyl hydroperoxide were purchased from Sigma Chemicals, St. Louis, MO, USA. NADPH and 1-chloro-2,4-dinitrobenzene were obtained from Oriental Yeast, Tokyo, and Wako Pure Chemicals, Osaka, respectively. Linoleic acid hydroperoxide was obtained by air oxidation of linoleic acid under darkness for $72 \mathrm{hr}$ at room temperature. Formation of linoleic-OOH was determined by the increase in absorbance at $233 \mathrm{~nm}$. All other chemicals used were of analytical reagent grade.

\section{Statistical analyses}

Data are expressed as the mean of triplicate incubations. The significance of the difference was calculated by Student's $t$-test, and $\mathrm{P}$ values $<0.05$ were taken as significant.

\section{RESULTS}

Figure 1 shows the effect of $\mathrm{t}-\mathrm{BuOOH}$ and $\mathrm{CuOOH}$ on microsomal glutathione $S$-transferase activity. When microsomes were incubated with various concentrations of t-BuOOH or $\mathrm{CuOOH}$ at room temperature for $30 \mathrm{~min}$, the transferase activity in microsomes was increased to $151 \%$ by $0.1 \mathrm{mM}$ t-BuOOH and to $152 \%$ by $0.025 \mathrm{mM}$ $\mathrm{CuOOH}$ as compared to the control. On the other hand, a $35 \%$ - and a $75 \%$-decrease in microsomal glutathione $S$ transferase activity was observed when microsomes were incubated with $2 \mathrm{mM} \mathrm{t}-\mathrm{BuOOH}$ and $1 \mathrm{mM} \mathrm{CuOOH}$, respectively. Table 1 further shows the fact that small amounts of glutathione enhanced the $\mathrm{t}-\mathrm{BuOOH}$-induced activation of glutathione $S$-transferase; i.e., glutathione $S$-transferase activity was increased to $151 \%$ by $0.1 \mathrm{mM}$

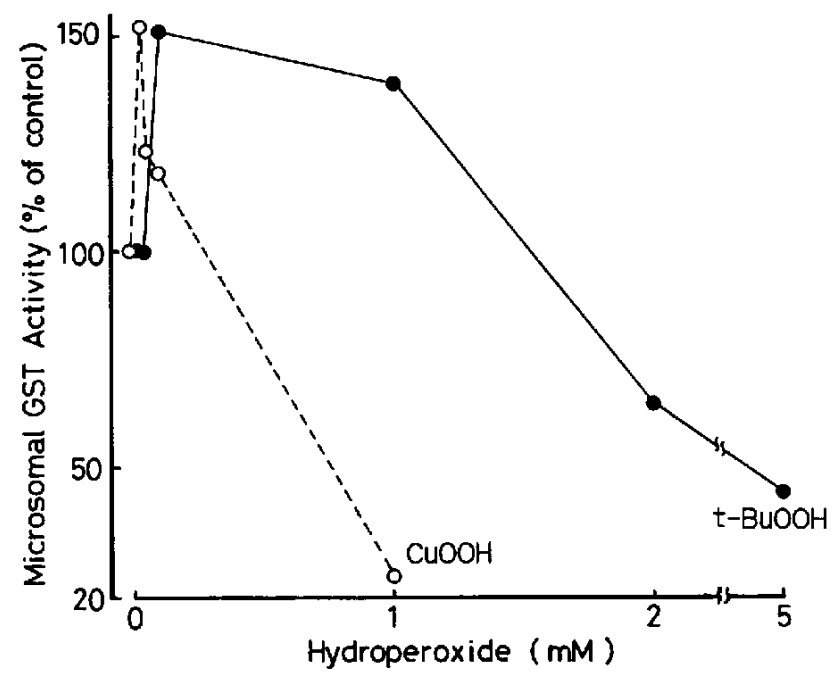

Fig. 1. Effect of $t$-butyl hydroperoxide (t-BuOOH) or cumene hydroperoxide (CuOOH) on liver microsomal glutathione $S$ transferase (GST) activity. Microsomes were incubated with various concentrations of $\mathrm{t}$ - $\mathrm{BuOOH}$ or $\mathrm{CuOOH}$ in $0.05 \mathrm{M}$ potassium phosphate buffer ( $\mathrm{pH} 7.4)$ at room temperature for $30 \mathrm{~min}$ after which microsomal GST activity was measured as described under Materials and Methods. Each point shows the mean in triplicate determinations.

Table 1. Effect of glutathione (GSH) on $t$-butyl hydroperoxide (t-BuOOH)-induced increase in microsomal glutathione $S$-transferase (GST) activity in vitro

\begin{tabular}{lrcc}
\hline Treatment & $\begin{array}{c}\text { GSH } \\
(\mu \mathrm{M})\end{array}$ & $\begin{array}{c}\text { GST activity } \\
(\mu \mathrm{mol} / \mathrm{mg} / \mathrm{min})\end{array}$ & $\%$ of control \\
\hline Control & 0 & 0.095 & \\
& 5 & 0.106 & \\
& 10 & 0.103 & \\
& 25 & 0.094 & \\
& 50 & 0.094 & \\
$\mathrm{t}-\mathrm{BuOOH}(100 \mu \mathrm{M})$ & 0 & 0.082 & 151 \\
& 5 & 0.143 & 175 \\
& 10 & 0.185 & 171 \\
& 0.176 & 163 \\
& 50 & 0.153 & 180 \\
& 100 & 0.169 & 113 \\
\hline
\end{tabular}

Microsomes were incubated with $\mathrm{t}-\mathrm{BuOOH}$ in the presence or absence of various concentrations of $\mathrm{GSH}$ in $0.05 \mathrm{M}$ potassium phosphate buffer ( $\mathrm{pH} \mathrm{7.4)} \mathrm{at} \mathrm{room} \mathrm{temperature} \mathrm{for} 30$ min. Values are presented as the mean of triplicate determinations.

t-BuOOH alone and to $171 \%$ by a combination of t-BuOOH with $10 \mu \mathrm{M}$ glutathione. However, the effect of glutathione on the activation of the transferase by $t$ $\mathrm{BuOOH}$ was lost when $0.1 \mathrm{mM}$ glutathione was used. The 

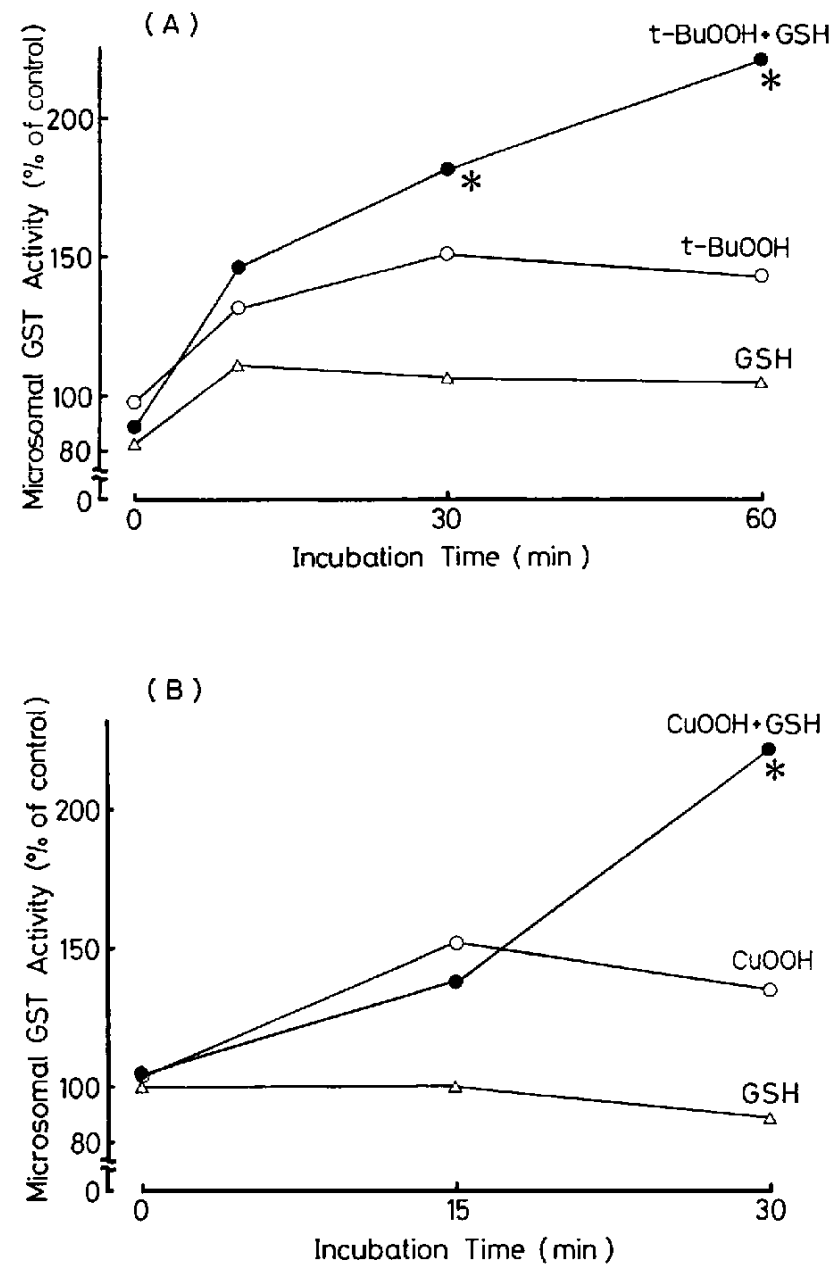

Fig. 2. Time course for glutathione $S$-transferase (GST) activity in microsomes treated with $t$-butyl hydroperoxide (t-BuOOH) (A) or cumene hydroperoxide (CuOOH) (B). Microsomes were incubated with $100 \mu \mathrm{M}$ t-BuOOH or $25 \mu \mathrm{M} \mathrm{CuOOH}$ in the presence or absence of one-tenth amounts of glutathione (GSH) against each hydroperoxide in $0.05 \mathrm{M}$ potassium phosphate buffer (pH 7.4) at room temperature for the indicated times. Each point shows the mean of triplicate determinations. The control value of microsomal GST activity at $0 \mathrm{~min}$ was $0.100 \pm 0.011 \mu \mathrm{mol}$ products $/ \mathrm{mg} / \mathrm{min}$. ${ }^{*} \mathrm{P}<0.05$ peroxide treated vs. peroxide $+\mathrm{GSH}$ treated.

incubation of microsomes with $\mathrm{CuOOH}(25 \mu \mathrm{M})$ combined with glutathione $(1.25 \mu \mathrm{M})$ also increased microsomal glutathione $S$-transferase activity to $175 \%$ as compared to $152 \%$ by $\mathrm{CuOOH}$ alone.

Figure 2 shows the time-course effect of $0.1 \mathrm{mM}$ t$\mathrm{BuOOH}$ or $0.025 \mathrm{mM} \mathrm{CuOOH}$ on microsomal glutathione $S$-transferase activity in the presence or absence of glutathione. Glutathione $S$-transferase activity was increased with increasing incubation time of microsomes in the presence of $\mathrm{t}-\mathrm{BuOOH}$ plus $10 \mu \mathrm{M}$ glutathione and reached 2.2-fold of the control at $60 \mathrm{~min}$. However, transferase activity showed a maximum (1.5-fold) at $30 \mathrm{~min}$

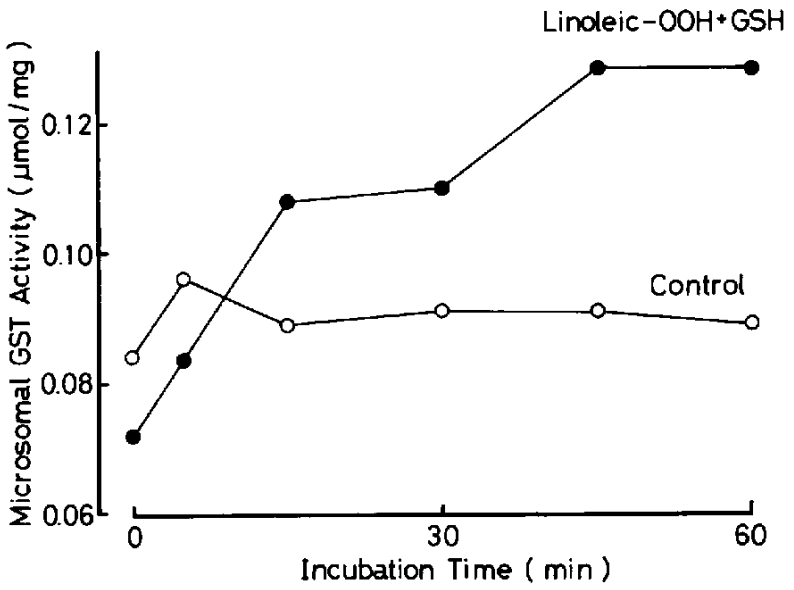

Fig. 3. Time course for glutathione $S$-transferase (GST) activity in microsomes treated with linoleic acid hydroperoxide (Linoleic$\mathrm{OOH}$ ). Microsomes were incubated with $10 \mu \mathrm{M}$ linoleic-OOH in the presence of $1 \ell \mathrm{M}$ glutathione (GSH) in $0.05 \mathrm{M}$ potassium phosphate buffer $(\mathrm{pH} \mathrm{7.4)}$ at room temperature for the indicated times. Each point shows the mean of triplicate determinations.

for t-BuOOH without glutathione. Similar time-dependent increase in microsomal glutathione $S$-transferase activity was also observed in the treatment of microsomes with $\mathrm{CuOOH}$ in the presence of glutathione, although a maximum effect of $\mathrm{CuOOH}$ per se on the transferase activity was seen at $15 \mathrm{~min}$. Microsomal glutathione $S$-transferase activity was also increased to $145 \%$ of the control when microsomes were incubated with $10 \mu \mathrm{M}$ linoleic-OOH in the presence of $1 \mu \mathrm{M}$ glutathione for $60 \mathrm{~min}$ (Fig. 3). A small increase (115\% of control) in the transferase activity was observed by linoleic-OOH alone or by arachidonic$\mathrm{OOH}$ plus glutathione.

The effect of thiol compounds was examined to confirm the effect of a sulfhydryl group on the enhancement of t$\mathrm{BuOOH}$-induced activation of glutathione $S$-transferase. For microsomes treated with $0.1 \mathrm{mM}$ t-BuOOH in the presence of $10 \mu \mathrm{M}$ of thiol compounds such as glutathione, dithiothreitol or cysteine, only glutathione enhanced the t-BuOOH-induced activation of the transferase (Fig. 4). Table 2 shows the effect of high concentrations $(5 \mathrm{mM})$ of dithiothreitol on $\mathrm{t}-\mathrm{BuOOH}$-induced activation of microsomal glutathione $S$-transferase. Microsomal glutathione $S$-transferase activity that was increased to 2.0-fold upon treatment with $0.1 \mathrm{mM} \mathrm{t-BuOOH}$ in the presence of $10 \mu \mathrm{M}$ glutathione was recovered to the control level by the addition of dithiothreitol; it was not affected by dithiothreitol in the case of treatment of microsomes with t-BuOOH alone.

Since microsomal glutathione $S$-transferase also possesses peroxidase activity, the effect of $\mathrm{t}-\mathrm{BuOOH}$ on GSH peroxidase activity in microsomes was studied. When 


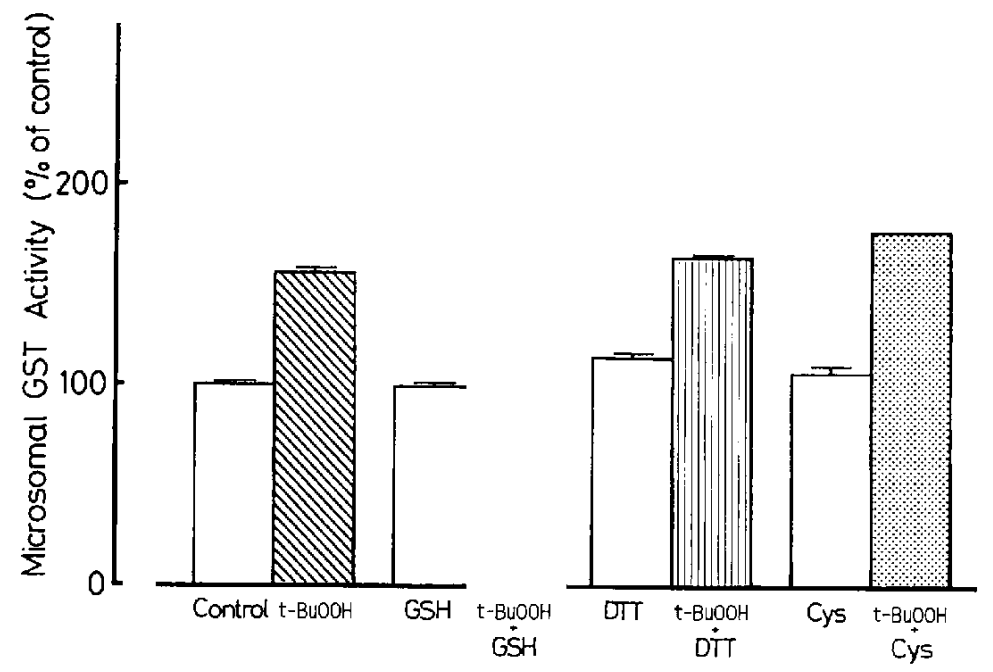

Fig. 4. Effect of thiol compounds on $t$-butyl hydroperoxide ( $\mathrm{t}-\mathrm{BuOOH}$ )-induced activation of microsomal glutathione $S$-transferase (GST). Microsomes were incubated with $100 \mu \mathrm{M}$ t-BuOOH in the presence or absence of thiol compounds (glutathione, GSH; dithiothreitol, DTT; cysteine, Cys) (the ratio of the hydroperoxide to thiol compounds was $1: 0.1$ ) in $0.05 \mathrm{M}$ potassium phosphate buffer ( $\mathrm{pH} 7.4$ ) at room temperature for $30 \mathrm{~min}$. Each column represents the mean of triplicate determinations. Control value of the microsomal GST activity was $0.074 \mu \mathrm{mol}$ products/ $\mathrm{mg} / \mathrm{min}$.
Table 2. Effect of dithiothreitol (DTT) on $t$-butyl hydroperoxide (t-BuOOH)-induced activation of microsomal glutathione $S$-transferase (GST)

\begin{tabular}{lccc}
\hline Treatment & $\begin{array}{c}\text { DTT } \\
(5 \mathrm{mM})\end{array}$ & $\begin{array}{c}\text { GST activity } \\
(\mu \mathrm{mol} / \mathrm{mg} / \mathrm{min})\end{array}$ & \%0 of control \\
\hline Control & - & 0.096 & \\
& + & 0.081 & \\
t-BuOOH & - & 0.127 & 132 \\
& + & 0.109 & 134 \\
t-BuOOH + GSH & - & 0.211 & 219 \\
& + & 0.095 & 117 \\
\hline
\end{tabular}

Microsomes were incubated with $100 \mu \mathrm{M}$ t-BuOOH in the presence or absence of $10 \mu \mathrm{M}$ glutathione (GSH) for $30 \mathrm{~min}$ followed by an additional incubation with or without $5 \mathrm{mM}$ DTT in $0.05 \mathrm{M}$ potassium phosphate buffer $(\mathrm{pH} \mathrm{7.4)}$ for $15 \mathrm{~min}$ at room temperature. GST activity in the incubation mixtures was measured as described under Materials and Methods. Values are presented as the mean of triplicate determinations. microsomes were incubated with $0.1 \mathrm{mM} \mathrm{t}-\mathrm{BuOOH}$ in either the presence or absence of $10 \mu \mathrm{M}$ glutathione followed by centrifugation at $105,000 \times g$ for $60 \mathrm{~min}$ to remove residual $\mathrm{t}-\mathrm{BuOOH}$ and $\mathrm{GSH}$, glutathione $S$-transferase activity in treated microsomes remained at high levels: up to $164 \%$ of the control upon treatment with $t-$ $\mathrm{BuOOH}$ and up to $210 \%$ upon treatment with t-BuOOH plus glutathione. On the other hand, peroxidase activity in microsomes was decreased to $79 \%$ by $\mathrm{t}-\mathrm{BuOOH}$ alone and to $82 \%$ upon combination with glutathione (Table 3 ).

\section{DISCUSSION}

Previous studies indicate that liver microsomal glutathione $S$-transferase is activated by hydrogen peroxide via an oxidation of the sulfhydryl group in the transferase $(14,15)$. Our results show that microsomal glutathione $S$ transferase is also activated by organic hydroperoxides such as $\mathrm{t}-\mathrm{BuOOH}, \mathrm{CuOOH}$ or linoleic-OOH and that activation is enhanced by the presence of a small amount of glutathione.

It is well known that organic hydroperoxides are catalyt-

Table 3. Effect of $t$-butyl hydroperoxide (t-BuOOH) and glutathione (GSH) on microsomal glutathione $S$ transferase (GST) and peroxidase (GSH-Px) activities in vitro

\begin{tabular}{lcccc}
\hline Treatment & $\begin{array}{c}\text { GST } \\
(\mu \mathrm{mol} / \mathrm{mg} / \mathrm{min})\end{array}$ & $(\%)$ & $\begin{array}{c}\text { GSH-Px } \\
(\mu \mathrm{mol} / \mathrm{mg} / \mathrm{min})\end{array}$ & $(\%)$ \\
\hline Control & 0.105 & 100 & 0.053 & 100 \\
$\mathrm{t}-\mathrm{BuOOH}(100 \mu \mathrm{M})$ & 0.169 & 164 & 0.042 & 79 \\
$\mathrm{t}-\mathrm{BuOOH}(100 \mu \mathrm{M})+\mathrm{GSH}(10 \mu \mathrm{M})$ & 0.216 & 210 & 0.043 & 82 \\
\hline
\end{tabular}

Microsomes were incubated with $\mathrm{t}-\mathrm{BuOOH}$ in the presence or absence of GSH in $0.05 \mathrm{M}$ potassium phosphate buffer $(\mathrm{pH} 7.4)$ at room temperature for $30 \mathrm{~min}$ and then centrifuged at $105,000 \times \mathrm{g}$ for $60 \mathrm{~min}$. GST and GSH-Px activities in the pellets were measured afterwards. Values are presented as the mean of two experiments. 
ically decomposed by both heme- and non-heme-iron complexes followed by the production of free radicals, consequently resulting in lipid peroxidation (22-24). Maples et al. (25) reported that the administration of organic hydroperoxides to rats resulted in the oxidation of hemoglobin thiols. Since liver microsomes are rich in heme protein cytochrome $\mathrm{P}-450$, it is likely that free radicals formed via the hydroperoxide-cytochrome P-450 complex may attack the sulfhydryl group of microsomal glutathione $S$-transferase, consequently causing oxidative activation of the transferase. Since sulfur is oxidized through a reversible oxidation state such as sulfenic acid to an irreversible state, sulfinic acid and sulfonic acid (26), it is suggested that the cysteine residue of microsomal glutathione $S$-transferase is oxidized to sulfenic acid followed by disulfide bond formation, resulting in an activation of the transferase. Considering that high concentrations of t-BuOOH $(2 \mathrm{mM})$ or $\mathrm{CuOOH}(1 \mathrm{mM})$ markedly decreased microsomal glutathione $S$-transferase activity as compared to the activation of the enzyme at low concentrations, e.g., $100 \mu \mathrm{M} \mathrm{t}-\mathrm{BuOOH}$ or $25 \mu \mathrm{M}$ $\mathrm{CuOOH}$, it may therefore be presumed that too much organic hydroperoxide is causing other modifications of the enzyme.

Glutathione showed different effects on t-BuOOH-induced activation of microsomal glutathione $S$-transferase depending upon its concentration: glutathione at onetenth the $\mathrm{t}-\mathrm{BuOOH}$ concentration enhanced the hydroperoxide-induced activation of microsomal glutathione $S$ transferase, whereas glutathione produced no additive effect on the activation when it was present at the same or higher concentration than t-BuOOH (Table 1). An activation of microsomal glutathione $S$-transferase by $\mathrm{t}-\mathrm{BuOOH}$ in the presence of glutathione, which is reversed by dithiothreitol (Table 2), may arise from a mixed disulfide bond formation of the cysteine residue of the transferase with glutathione via thiyl radicals produced by the hydroperoxide-heme protein complex. Similar phenomena such as the potentiation of microsomal glutathione $S$-transferase activation by glutathione was also observed in hydrogen peroxide- and diamide-induced activation of microsomal glutathione $S$-transferase $(9,14)$. All these data confirm that oxidants in the presence of a small amount of glutathione accelerate a mixed-disulfide bond formation of microsomal glutathione $S$-transferase with glutathione thiol, resulting in an activation of the transferase. On the other hand, the effect of $\mathrm{t}-\mathrm{BuOOH}$ on the transferase activity was not depressed by dithiothreitol in the absence of glutathione. It is therefore suggested that hydroperoxides may oxidize microsomal glutathione $S$ transferase to different forms from disulfide bond formation. Although an irreversible oxidation of the cysteine residue to sulfinic acid and sulfonic acid may occur by t-
$\mathrm{BuOOH}$, we did not examine whether cysteic acid causes an activation of microsomal glutathione $S$-transferase. Lundquist and Morgenstern (27) also showed a small increase in microsomal glutathione $S$-transferase activity in isolated hepatocytes by treatment with $\mathrm{t}-\mathrm{BuOOH}$.

In our study, it was demonstrated that linoleic-OOH and arachidonic- $\mathrm{OOH}$ activate microsomal glutathione $S$ transferase. Considering that organic hydroperoxides or 4-hydroxyalkenals are used as substrates for microsomal glutathione $S$-transferase $(17,18)$, it is likely that toxic products from lipid peroxidation including fatty acid hydroperoxides or 4-hydroxyalkenals activate the transferase and are detoxified by the same enzyme, showing up-regulation of the transferase by its own substrates.

It is known that microsomal glutathione $S$-transferase also functions as glutathione peroxidase. However, the latter activity was not activated by $\mathrm{t}-\mathrm{BuOOH}$ per se or $\mathrm{t}$ BuOOH plus glutathione (Table 3). Although the mechanism of peroxidase activity in microsomal glutathione $S$ transferase is unknown, it may be considered that a conformational change caused by oxidation of the sulfhydryl group of the microsomal glutathione $S$-transferase by hydroperoxide or by hydroperoxide plus glutathione results in an activation of glutathione $S$-transferase, and that it may also be assumed that the binding affinity of the enzyme for cumene hydroperoxide or 1-chloro-2,4dinitrobenzene may be different. The peroxidase activity in purified microsomal glutathione $S$-transferase has been found to be activated by $N$-ethylmaleimide, like the transferase activity $(6,18,28)$, and we also observed the same phenomenon in the purified enzyme. However, glutathione peroxidase purified from mouse liver was not activated by the sulfhydryl agent (29). On the other hand, there is one report about the activation of glutathione peroxidase in microsomal fractions by a sulfhydryl agent (20), and another study showed that the peroxidase activity is not altered or decreased by $N$-ethylmaleimide or oxidized glutathione (30). In our laboratory, glutathione peroxidase activity in microsomes was not increased by $\mathrm{N}$-ethylmaleimide in spite of a 5 -fold increase in the glutathione $S$-transferase activity (data not shown). It is not clear but the environment around the glutathione $S$-transferase in microsomal membranes may contribute to an activation of the transferase and peroxidase in the crude enzyme. However, the discrepancy of activation between glutathione peroxidase and glutathione $S$-transferase needs to be investigated further.

In conclusion, rat liver microsomal glutathione $S$-transferase is activated by organic hydroperoxides in the presence or absence of glutathione, suggesting an activation by thiol oxidation of the transferase by free radicals produced from the hydroperoxide-heme protein complex. This activation may play an important role in the detoxifi- 
cation of toxic products from lipid peroxidation caused by oxidative stress.

\section{Acknowledgment}

We thank Ms. N. Omine for typing the manuscript.

\section{REFERENCES}

1 Jakoby, W.B. and Habig, W.H.: Glutathione transferase. In Enzymatic Basis of Detoxication, Edited by Jakoby, W.B., Vol. 2, pp. 63-94, Academic Press, New York (1980)

2 Habig, W.H.: Glutathione $S$-transferase: Versatile enzymes of detoxication. In Radioprotectors and Anticarcinogens, Edited by Nygaard, O.F. and Simic, M.G., pp. 169-190, Academic Press, New York (1983)

3 Morgenstern, R. and DePierre, J.W.: Microsomal glutathione $S$-transferase. Rev. Biochem. Toxicol, 7, 67-104 (1985)

4 Mannervik, B. and Danielson, U.H.: Glutathione transferases-structure and catalytic activity. CRC Crit. Rev. Biochem. 23, 283- 337 (1988)

5 DeJong, J.L., Morgenstern, R., Jornvall, H., DePierre, J.W. and Tu, C.-P.D.: Gene expression of rat and human microsomal glutathione $S$-transferases. J. Biol. Chem. 263, 84308436 (1988)

6 Morgenstern, R. and DePierre, J.W.: Microsomal glutathione transferase: Purification in unactivated form and further characterization of the activation process, substrate specificity and amino acid composition. Eur. J. Biochem. 134, 591 - 597 (1983)

7 Morgenstern, R., DePierre, J.W. and Jornvall, H.: Microsomal glutathione transferase; Primary structure. J. Biol. Chem. 260, 13976-13983 (1985)

8 Morgenstern, R., DePierre, J.W. and Ernster, L.: Activation of microsomal glutathione $S$-transferase activity by sulfhydryl reagents. Biochem. Biophys. Res. Commun. 87, 657-663 (1979)

9 Aniya, Y. and Anders, M.W.: Regulation of rat liver microsomal glutathione $S$-transferase activity by thiol/disulfide exchange. Arch. Biochem. Biophys. 270, 330-334 (1989)

10 Morgenstern, R., DePierre, J.W. and Ernster, L.: Reversible activation of rat liver microsomal glutathione $S$-transferase activity by 5,5'-dithiobis (2-nitrobenzoic acid) and 2,2'-dipyridyl disulfide. Acta Chem. Scand. B34, 229-230 (1980)

11 Morgenstern, R., Lundquist, G., Jornvall, H. and DePierre, J.W.: Activation of rat liver microsomal glutathione transferase by limited proteolysis. Biochem. J. 260, 577-582 (1989)

12 Aniya, Y.: Activation of liver microsomal glutathione $S$-transferase activity by heating. J. Pharmacobiodyn. 12, 235-240 (1989)

13 Aniya, Y. and Anders, M.W.: Activation of rat liver microsomal glutathione $S$-transferase by reduced oxygen species. J. Biol. Chem. 264, 1998-2002 (1989)

14 Aniya, Y. and Anders, M.W.: Activation of rat liver microsomal glutathione $S$-transferase by hydrogen peroxide: Role for protein-dimer formation. Arch. Biochem. Biophys. 296, $611-616$ (1992)

15 Aniya, Y. and Anders, M.W.: Activation of hepatic microsomal glutathione $S$-transferase by hydrogen peroxide and diamide. In Oxygen Radicals, Edited by Yagi, K., Kondo, M., Niki, E. and Yoshikawa, T., pp. 737-740, Elsevier, Amster- dam (1992)

16 Aniya, Y, and Naito, A.: Oxidative stress-induced activation of microsomal glutathione $S$-transferase in isolated rat liver. Biochem. Pharmacol, 45, 37-42 (1993)

17 Alin, P., Danielson, U.H. and Mannervik, B.: 4-Hydroxyalk-2enals are substrates for glutathione transferase. FEBS Lett. 179, $267-270(1985)$

18 Mosialou, E. and Morgenstern, R.: Activity of rat liver microsomal glutathione transferase toward products of lipid peroxidation and studies of the effect of inhibitors on glutathione-dependent protection against lipid peroxidation. Arch. Biochem. Biophys. 275, 289-294 (1989)

19 Habig, W.H., Pabst, M.J. and Jakoby, W.B.: Glutathione Stransferase. J. Biol. Chem. 249, 7130-7139 (1974)

20 Reddy, C.C., Tu, C.-P.D., Burgess, J.R., Ho, C.-Y., Scholz, R.W. and Massaro, E.J.: Evidence for the occurrence of selenium-independent glutathione peroxidase activity in rat liver microsomes. Biochem. Biophys. Res. Commun. 101, 970-978 (1981)

21 Lowry, O.H., Rosebrough, N.J., Farr, A.C. and Randall, R.J.: Protein measurement with the Folin phenol reagent. J. Biol. Chem. 193, 265-275 (1951)

22 Hrycay, E.G. and O'Brien, P.J.: Microsomal electron transport. II. Reduced nicotinamide adenine dinucleotide-cytochrome $b_{s}$ reductase and cytochrome P-450 as electron carriers in microsomal NADH-peroxidase activity. Arch. Biochem. Biophys. 160, 230-245 (1974)

23 Thornalley, P.J., Trotta, R.J. and Stern, A.: Free radical involvement in the oxidative phenomena induced by tert-butyl hydroperoxide in erythrocytes. Biochim. Biophys. Acta 759 , $16-22$ (1983)

24 Davies, M.J.: Detection of peroxy and alkoxyl radicals produced by reaction of hydroperoxides with heme-proteins by electron spin resonance spectroscopy. Biochim. Biophys. Acta 964, 28-35 (1988)

25 Maples, K.R., Kennedy, C.H., Jordan, S.J. and Mason, R.P.: In vivo thiyl free radical formation from hemoglobin following administration of hydroperoxides. Arch. Biochem. Biophys. 277, 402-409 (1990)

26 Poole, L.B. and Claiborne, A.: The non-flavin redox center of the streptococcal NADH peroxidase. II. Evidence for a stabilized cysteine-sulfenic acid. J. Biol. Chem. 264, 12330-12338 (1989)

27 Lundquist, G. and Morgenstern, R.: Studies on the activation of rat liver microsomal glutathione transferase in isolated hepatocytes. Biochem. Pharmacol. 43, $131-135$ (1992)

28 McLellan, L.I., Wolf, C.R. and Hayes, J.D.: Human microsomal glutathione $S$-transferase. Its involvement in the conjugation of hexachlorobuta-1,3-diene with glutathione. Biochem. J. 258, 87-93 (1989)

29 Andersson, C., Söderstrom, M. and Mannervik, B.: Activation and inhibition of microsomal glutathione transferase from mouse liver. Biochem. J. 249, 819-823 (1988)

30 Nagasaka, Y., Fujii, S. and Kaneko, T.: Microsomal glutathione-dependent protection against lipid peroxidation acts through a factor other than glutathione peroxidase and glutathione $S$-transferase in rat liver. Arch. Biochem. Biophys. 274, 82-86 (1989) 